\title{
Decisive role of transport rate of products for zeolite para-selectivity: Effect of coke deposition and external surface silylation on activity and selectivity of HZSM-5 in alkylation of toluene
}

\author{
Jiří Čejka, Naděžda Žilková, and Blanka Wichterlová \\ J. Heyrovsky Institute of Physical Chemistry, Academy of Sciences of the Czech Republic, \\ CZ-182 23 Prague 8, Czech Republic \\ Gabriele Eder-Mirth and Johannes A. Lercher \\ Faculty of Chemical Technology, University of Twente, 7500 AE Enschede, the Netherlands
}

\begin{abstract}
Toluene alkylation with methanol and ethylene over HZSM-5 zeolites has been investigated in order to understand the effects of deposited "coke" and postsynthesis surface silylation on the toluene conversion and product selectivity. Long time-on-stream kinetic runs, performed under conditions in which total toluene conversion did not decrease but concentration of coke continuously increased were used to follow the changes in the individual xylene selectivity, the activity of the external surface, and the transport rates of individual xylene isomers. A very small increase in ortho- and para-xylene selectivity, no changes in xylene diffusivities, but a substantial decrease in the activity of the external surface were observed with increasing coke deposition. Under severe reaction conditions when coking caused a substantial decrease in toluene conversion, nearly no increase in para-xylene or para-ethyltoluene selectivity was found. The silylation of ZSM-5 zeolite with tetraethylorthosilicate blocked active sites on the external zeolite surface and decreased considerably the diffusivities of xylenes and ethyltoluenes. This modification also increased substantially the para-selectivity at high toluene conversions. Comparing the effect of coke deposition and surface silylation on the para-selectivity it is concluded that a decrease in the transport rates of xylenes is decisive for an enhancement of the para-selectivity, whereas secondary isomerization of para-isomers on the external surface plays a minor role.
\end{abstract}

Keywords: Transport; H-ZSM-5; para-selectivity; toluene alkylation

\section{INTRODUCTION}

Alkylation of aromatic hydrocarbons over molecular sieves, particularly over shape-selective medium pore zeolites (e.g., ZSM-5, -11, -22) has been extensively investigated..$^{1-11}$ The contribution of the initial alkylation step to the product distribution of the dialkylbenzene isomers, their further isomerization in the zeolite channels and on the external surface, and the role of the transport rates of the individual isomers for the resulting selectivity of zeolites are still discussed..$^{12-15}$ It has been shown that a high para-selectivity in the alkylation or disproportionation of toluene can be achieved via chemical modification of the zeolite crystal surface, using deposition of bulky silicon or magnesium compounds or organic molecules that do not penetrate into

Address reprint requests to Dr. Wichterlová at the J. Heyrovský Institute of Physical Chemistry, Academy of Sciences of the Czech Republic; Dolejškova 3, CZ-182 23 Prague 8, Czech Republic Received 10 August 1995; accepted 8 January 1996 the zeolite channels. This is usually ascribed to the blocking of active sites on the external surface and/or to decreasing the free diameter of channel entrances. $2,10,13,16$

Similarly, the effect of coke deposits on the paraselectivity of alkylation reactions is ascribed to site blocking and pore mouth narrowing as in the case of chemical modification of the external surface. However, until now it has not been clear what is the most important factor affecting the resulting para-selectivity, the isomerization of $p$-dialkylaromatics on the external zeolite surface or the narrowing of the pore opening affecting the transport rates of the individual products. ${ }^{1,2,9,16-19}$

This contribution addresses the effect of coke deposits and the role of prereaction surface silylation on the activity and para-selectivity of HZSM- 5 zeolites in toluene alkylation with methanol and ethylene. The zeolites were characterized by FT i.r. spectroscopy, sorption capacity for argon, and the concentration of coke deposits. The location of coke deposits and its effect on 
the catalytic reaction are evaluated on the basis of the zeolite sorption capacities reflected in inner void volume, the external surface activity monitored by transformation of 1,3,5-triisopropylbenzene (1,3,5-TIPB) and uptake measurements of the individual xylene and ethyltoluene isomers.

\section{EXPERIMENTAL}

The acid form of ZSM-5 zeolite (Si $/ \mathrm{Al}=22.5$, crystal size 1-2 $\mu \mathrm{m}$ ) was prepared by ion exchange of the sodium form with $0.5 \mathrm{M}$ nitric acid. The silylated sample ( $8.5 \mathrm{wt} \%$ of $\mathrm{Si}$ ) was prepared by suspending the zeolite powder in dry $n$-hexane in which a calculated amount of tetraethylorthosilicate was added. ${ }^{13,16}$

The number of strong acid sites was calculated from the high temperature peak of the temperatureprogrammed desorption $(20 \mathrm{~K} / \mathrm{min})$ of ammonia (t.p.d.a.) performed in a helium stream of $5.0 \mathrm{ml} / \mathrm{min}$ on zeolites pretreated at $770 \mathrm{~K}$ for $1 \mathrm{hr}$. The zeolite was equilibrated in an ammonia stream (10\% ammonia in nitrogen) at $373 \mathrm{~K}$ for $0.5 \mathrm{~h}$, then in helium at the same temperature for $0.5 \mathrm{~h}$. The zeolite void volume was estimated from the sorption capacity for argon measured in a static apparatus at $13.33 \mathrm{kPa}$ of argon at $80 \mathrm{~K}$ on samples pretreated at $720 \mathrm{~K}$ in a vacuum of $10^{-1} \mathrm{~Pa}$ for $16 \mathrm{~h}$.

Toluene alkylation with methanol (at $570 \mathrm{~K}$ ) or ethylene (at $620 \mathrm{~K}$ ) was carried out in a vapor phase continuous down-flow glass microreactor under atmospheric pressure, at WHSV $10.0 \mathrm{~h}^{-1}$ and different timeon-streams (T-O-S). The nitrogen (carrier gas) was saturated with toluene at $333 \mathrm{~K}(18.5 \mathrm{vol} \%)$ and separately with methanol at $306 \mathrm{~K}$ (or ethylene) to establish a toluene/methanol (ethylene) molar ratio of 3.8. The individual kinetic runs were stopped at 55, 215, 840, and $1440 \mathrm{~min}$. To attain a substantial coke deposition and a decrease in toluene conversion, the zeolite was treated with ethylene for $15 \mathrm{~h}$ at $620 \mathrm{~K}$ (ethylene concentration 90 vol\%, WHSV $5.0 \mathrm{~h}^{-1}$ ). On the coked zeolitcs standard tcsts of tolucnc alkylation with methanol as well as with ethylene were carried out under the conditions given above.

After each reaction run the zeolite was purged with the pure carrier gas at the reaction temperature until the effluent gas was free of the reactants and products (at least for $30 \mathrm{~min}$ ). The zeolite sample was subsequently characterized with respect to the concentration of Brønsted acid sites (FT i.r., t.p.d.a.), sorption capacity for argon, the concentration of deposited coke, and external surface activity. The amount of coke formed during the alkylation reaction was estimated gravimetrically by burning the sample in air in a static apparatus at $820 \mathrm{~K}$ for $16 \mathrm{~h}$. The activity of the external surface of parent, silylated, and coked zeolites was tested via the conversion of 1,3,5-triisopropylbenzene (TIPB that is assumed to be unable to access the ZSM- 5 channels) at $570 \mathrm{~K}$ and WHSV $0.5 \mathrm{~h}^{-1}$.

The reaction products were analyzed using an online high resolution gas chromatograph HewlettPackard 5890 series II with a Supelcowax 10-capillary column (30 m length, inner diameter $0.2 \mathrm{~mm}$, phase
Table 1 Toluene alkylation with methanol over fresh HZSM-5. $\mathrm{T}-\mathrm{O}-\mathrm{S}$ dependence of concentration of $\mathrm{OH}$ groups, Ar sorption capacity, coke concentration, activity in 1,3,5-TIPB transformation, and toluene conversion and xylene isomer selectivity

\begin{tabular}{lccccc}
\hline T-O-S (min) & 0 & 55 & 215 & 840 & 1440 \\
\hline OH (mmol/g) & 0.75 & 0.69 & 0.68 & 0.61 & 0.58 \\
Ar (mmol/g) & 5.42 & 5.25 & 5.22 & 4.97 & 4.44 \\
Coke (wt\%) & 0 & 0.53 & 0.77 & 1.28 & 2.11 \\
1,3,5-TIPB conv. (\%) & 84.0 & 32.0 & 26.0 & 22.0 & 14.0 \\
T + MeOH conv. (\%) & & 15.8 & 16.3 & 16.3 & 16.4 \\
p-Xylene (mol\%) & & 26.6 & 26.8 & 27.5 & 28.0 \\
m-Xylene (mol\%) & & 46.3 & 44.0 & 38.2 & 37.3 \\
o-Xylene (mol\%) & & 27.1 & 29.2 & 34.3 & 34.7 \\
\hline
\end{tabular}

thickness $0.2 \mu \mathrm{m}$ ) combined with FI and MS (5971A) detectors.

The diffusivities of the individual xylene and ethyltoluene isomers in parent, silylated, and coked zeolites were investigated by means of time-resolved transmission absorption $F T$ i.r. spectroscopy using a Bruker IFS 88 spectrometer (typical resolution $4 \mathrm{~cm}^{-1}$ ). These experiments have been done under conditions enabling us to pump the system differentially in a sample compartment that can be evacuated to pressures below $10^{-4}$ $\mathrm{Pa}$. The xylene and ethyltoluene isomers were introduced into the vacuum system via a gas inlet manifold. The activated zeolite was mixed with $0.1 \mathrm{~Pa}$ of the adsorbate at $373 \mathrm{~K}$ until adsorption-desorption equilibrium was achieved. During adsorption, i.r. spectra were collected with time resolutions between $10 \mathrm{~s}$ and 10 min, depending on the adsorption rates of the substances.

\section{RESULTS AND DISCUSSION}

\section{Nondeactivated zeolite}

The activity and selectivity of HZSM-5 for toluene alkylation with methanol after different T-O-S and the corresponding zeolite void volume, the number of bridging $\mathrm{OH}$ groups, the concentration of coke, and

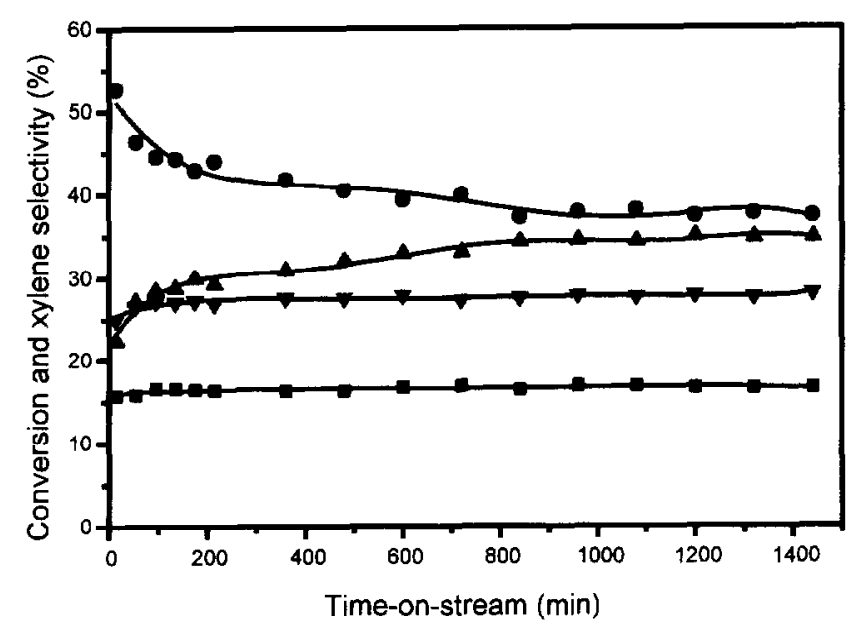

Figure 1 T-O-S dependence of toluene conversion ( 0 ) and $x y$ lene selectivity (para-, $\nabla$; meta-, 6 ; ortho, $\mathbf{A}$ ) in toluene alkylation with methanal. 
ABSORBANCE [arb.units]

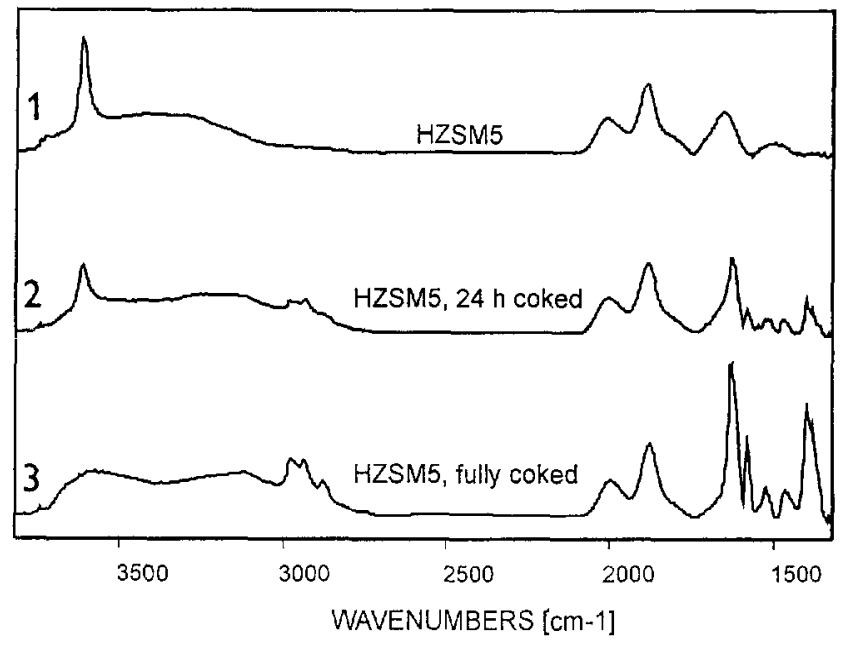

Figure 2 The i.r. spectra of ZSM-5; parent (1), after $24 \mathrm{~h}$ of toluene alkylation with methanol (2), after deactivation with ethylene (3).

the external surface activity are compiled in Table 1. Mild reaction conditions were chosen to obtain a constant toluene conversion level during a reaction run (Figure 1). With increasing T-O-S a continuous increase in the amount of formed coke took place (Table 1). Although toluene conversion was constant with T-O-S,

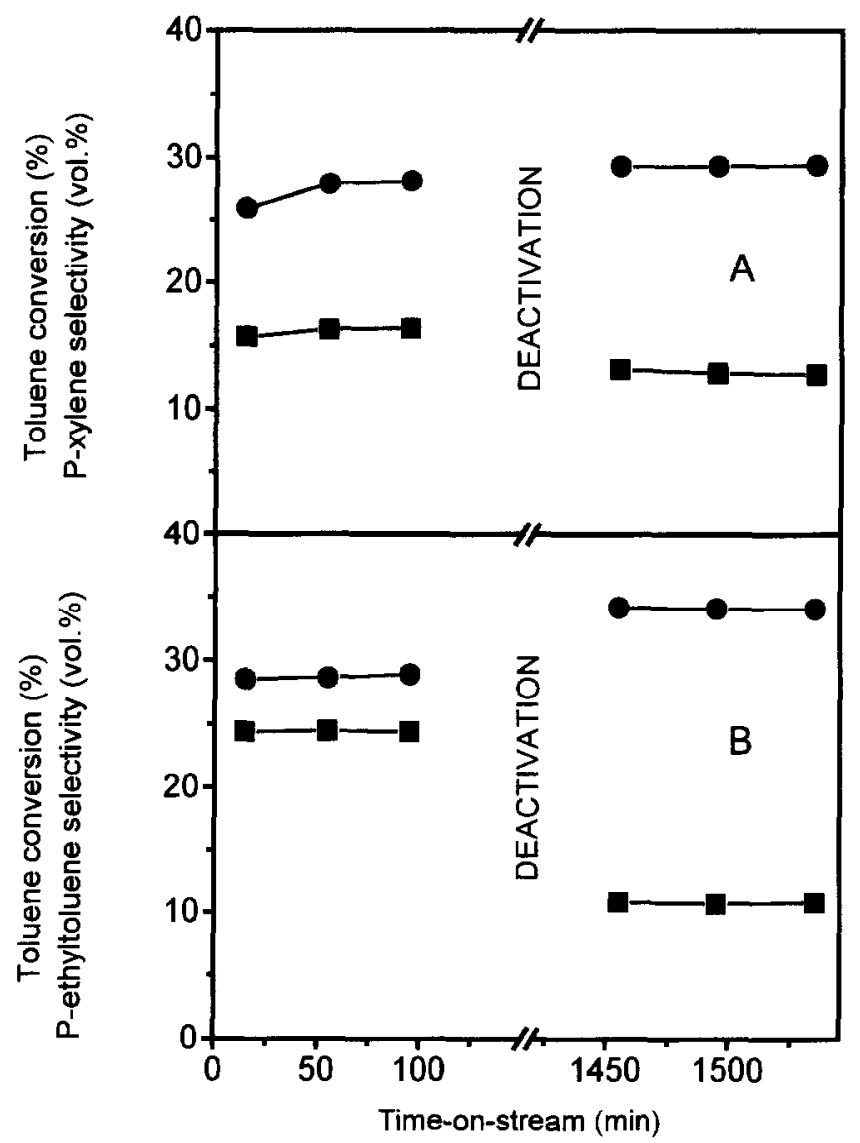

Figure 3 Effect of deactivation by ethylene (coked zeolite) on toluene conversion $(\boldsymbol{D})$ and $p$-xylene or $p$-ethyltoluene selectivity $(O)$ in toluene alkylation with methanol $(A)$ and ethylene $(B)$. coke deposits caused changes in the product composition. A continuous decrease in $m$-xylene selectivity ( 46.4 $\rightarrow 37.3 \%$ ) and a slight increase in $p$-xylene and $o$-xylene selectivity $(26.6 \rightarrow 28.0$ and $27.1 \rightarrow 34.7$, respectively) were observed. A substantial decrease in 1,3,5-TIPB conversion (monitoring the concentration of strong acid sites located on the external surface) with increasing amounts of coke deposits was also observed. Already after 55 min toluene alkylation with methanol, the conversion of 1,3,5-TIPB was less than $40 \%$ of the initial value and decreased further continuously. The substantial decrease in the external surface activity within $24 \mathrm{~h}$ of reaction together with a constant toluene conversion indicates that external surface sites do not contribute significantly to the zeolite alkylation activity. On the other hand, a decrease in the number of free bridging $\mathrm{Si}-\mathrm{OH}-\mathrm{Al}$ groups and of the zeolite void volume with T-O-S of about 25-30\% (after $24 \mathrm{~h}$ on stream) indicated that coke and irreversibly adsorbed molecules were located throughout the ZSM-5 crystals and not only on the external surface of the crystals. The presence of these deposits was associated with an increasing intensity of an i.r. absorption band at $1,615 \mathrm{~cm}^{-1}$, which can be attributed to $m$-xylene strongly bound to bridging $\mathrm{Si}-\mathrm{OH}-\mathrm{Al}$ groups (Figure 2). It should be mentioned also that polymethylated benzenes and coke (which might be formed under these conditions) can contribute to this band.

It can be supposed that $o$ - and $p$-xylenes are preferably formed in the first alkylation step inside the zeolite because of a higher reactivity of 0 - and $p$-positions of toluene. Thus, $m$-xylene should be formed by isomerization of these primary alkylation products. Because of its low diffusivity, $m$-xylene spends a substantially longer time in the ZSM-5 channel system, and its concentration in the adsorbed phase increases continuously with T-O-S. As the diffusivity of $p$-xylene is at least 100 times higher than that of $o$-xylene and comparable intrinsic reaction rates of $m$-xylene formation from $p$ and $o$-xylenes are reported, ${ }^{15}$ it can be supposed that $m$-xylene is formed preferentially from $o$-xylene, which

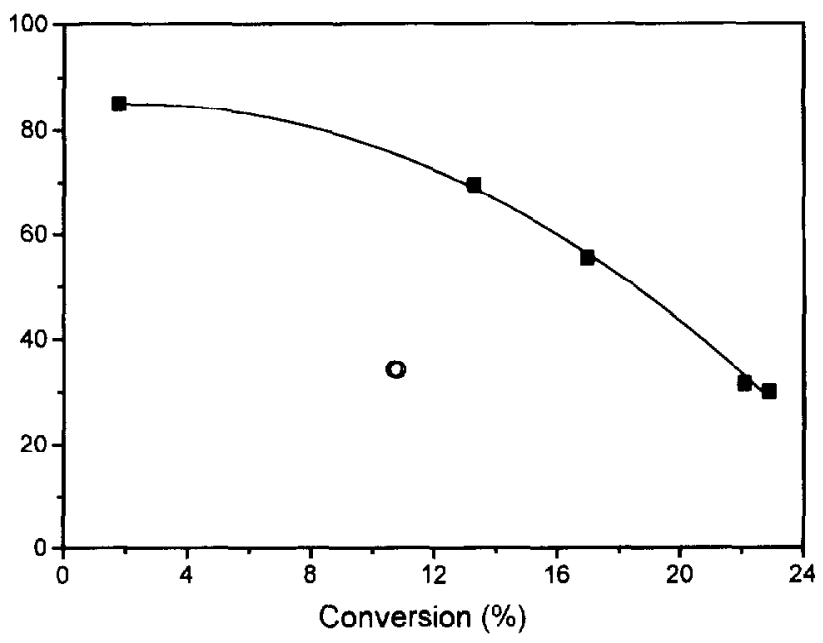

Figure 4 Conversion versus $p$-selectivity relationship for HZSM-5 zeolite at different WHSV (E) and HZSM-5 after deactivation by ethylene (O). 
Transport rate and zeolite para-selectivity: J. Čejka et al.

Table 2 Toluene alkylation with methanol over fresh and coked ZSM-5

\begin{tabular}{|c|c|c|c|c|c|c|}
\hline \multirow[b]{2}{*}{ Time-on-stream (min) } & \multicolumn{3}{|c|}{ Fresh ZSM-5 } & \multicolumn{3}{|c|}{ After deactivation with ethylene } \\
\hline & 15 & 55 & 95 & 15 & 55 & 95 \\
\hline Toluene conversion (\%) & 15.7 & 16.3 & 16.4 & 13.1 & 12.8 & 12.7 \\
\hline \multicolumn{7}{|l|}{ Product distribution (vol $\%$ ) } \\
\hline Benzene & 1.6 & 0.5 & 0.3 & 0 & 0 & 0 \\
\hline Ethylbenzene & 0.6 & 0.4 & 0.3 & 0 & 0 & 0 \\
\hline p-Xylene & 19.5 & 21.7 & 21.9 & 25.8 & 25.9 & 26.0 \\
\hline$m$-Xylene & 36.7 & 30.7 & 28.7 & 23.3 & 23.2 & 22.8 \\
\hline o-Xylene & 19.1 & 25.1 & 27.4 & 38.8 & 39.3 & 39.6 \\
\hline p-Ethyltoluene & 3.8 & 3.6 & 3.0 & 0.2 & 0.2 & 0.2 \\
\hline$m$-Ethyltoluene & 7.7 & 5.1 & 4.2 & 0.3 & 0.3 & 0.3 \\
\hline$o$-Ethyltoluene & 0.4 & 0.3 & 0.2 & 0 & 0 & 0 \\
\hline Pseudocumene & 4.9 & 7.0 & 7.5 & 8.3 & 8.2 & 8.1 \\
\hline Hemimellitene & 0.3 & 0.3 & 0.3 & 0 & 0 & 0 \\
\hline Higher aromatics & 5.6 & 5.1 & 6.4 & 3.3 & 3.1 & 3.1 \\
\hline \multicolumn{7}{|l|}{ Xylene selectivity (\%) } \\
\hline$p$ Xylene & 25.0 & 26.6 & 27.1 & 29.3 & 29.3 & 29.4 \\
\hline$m$ Xylene & 52.7 & 46.3 & 44.5 & 26.5 & 26.3 & 25.8 \\
\hline oXylene & 22.3 & 27.1 & 28.4 & 44.2 & 44.4 & 44.8 \\
\hline
\end{tabular}

spends much more time in zeolite channels than $p$ xylene. The increasing coverage of Brønsted acid sites by strongly bound $m$-xylene and probably also polymethylated benzenes or coke leads, thus, to a continuous decrease in the rate of $m$-xylene formation.

\section{Zeolite with deposited coke}

To obtain highly coked zeolite samples, ethylene was fed overnight over HZSM-5 zeolite at $620 \mathrm{~K}$. Coked HZSM-5 contained 5.2 wt $\%$ of coke. Figure 3 and Table 2 provide the T-O-S dependence of the toluene conversion and selectivity to $p$-xylene and p-ethyltoluene on the parent and coked zeolite. Toluene conversion decreased for the methylation reaction from 16.5 to $13.0 \%$ and for the ethylation reaction from 24.4 to $10.8 \%$. This corresponds to higher steric hindrances in the coked zeolite for ethyltoluenes compared with $x y-$ lenes.

A decrease in the toluene conversion is accompanied by changes in the product distribution. However, after a severe zeolite deactivation in toluene methylation, in addition to xylenes, ethyltoluenes, higher aromatics, and particularly pseudocumene were also observed, whereas in toluene ethylation selectivity to ethyltolu- enes was $97.0-98.0 \%$, and formation of secondary products was substantially suppressed. As for composition of xylenes and ethyltoluenes both p-isomers were found in a higher concentration with coked zeolite. This is not surprising as in both reactions toluene conversion was substantially lower for coked zeolite compared with the parent one. Figure 4 depicts the dependence of $p$ selectivity on conversion for toluene alkylation with ethylene (obtained by changing WHSV values at $620 \mathrm{~K}$ ). Comparing the p-selectivity of the coked ZSM- 5 with the $p$-selectivity of the parent ZSM- 5 at the same conversion level it is evident that the higher p-selectivity of the coked ZSM-5 was only apparent, and on the contrary the coke deposits affect negatively the zeolite paraselectivity (cf. Tables 2 and 3 and Figure 3).

\section{Silylated ZSM-5}

The silylated zeolite exhibited a sharp decrease in conversion in the toluene alkylation with ethylenc with T-O-S in contrast to parent HZSM-5 (Figure 5). This decrease in conversion is probably caused by higher transport hindrances in silylated ZSM-5 for bulkier products. Simultaneously, a substantial increase in $p$ ethyltoluene selectivity was observed $(34.0 \rightarrow 95.0$

Table 3 Toluene alkylation with ethylene over fresh and coked ZSM-5

\begin{tabular}{|c|c|c|c|c|c|c|}
\hline \multirow[b]{2}{*}{ Time-on-stream (min) } & \multicolumn{3}{|c|}{ Fresh ZSM-5 } & \multicolumn{3}{|c|}{ After deactivation with ethylene } \\
\hline & 15 & 55 & 95 & 15 & 55 & 95 \\
\hline Toluene conversion (\%) & 24.4 & 24.5 & 24.4 & 10.8 & 10.7 & 10.8 \\
\hline \multicolumn{7}{|l|}{ Product distribution (vol\%) } \\
\hline Benzene & 3.6 & 3.4 & 3.3 & 0 & 0 & 0 \\
\hline Ethylbenzene & 3.2 & 3.0 & 3.0 & 0 & 0 & 0 \\
\hline$p$-Xylene & 1.5 & 1.4 & 1.3 & 0 & 0 & 0 \\
\hline$m$-Xylene & 2.5 & 2.3 & 2.2 & 0 & 0 & 0 \\
\hline$\alpha$ Xylene & 0.9 & 0.9 & 0.9 & 0 & 0 & 0 \\
\hline p-Ethyltoluene & 23.8 & 24.2 & 24.4 & 33.3 & 33.4 & 33.5 \\
\hline$m$-Ethyltoluene & 53.7 & 54.6 & 54.7 & 60.2 & 60.7 & 60.9 \\
\hline o-Ethyltoluene & 5.9 & 5.8 & 5.5 & 3.7 & 3.7 & 3.8 \\
\hline Higher aromatics & 4.9 & 4.5 & 4.8 & 2.8 & 2.2 & 1.8 \\
\hline \multicolumn{7}{|l|}{ Ethyltoluene selectivity (\%) } \\
\hline$p$-Ethyltoluene & 28.5 & 28.6 & 28.9 & 34.2 & 34.1 & 34.1 \\
\hline$m$-Ethyltoluene & 64.4 & 64.5 & 64.6 & 62.0 & 62.1 & 62.0 \\
\hline o-Ethyltoluene & 7.1 & 6.9 & 6.5 & 3.8 & 3.8 & 3.9 \\
\hline
\end{tabular}


mol\%). The surface silylation resulted in an annihilation of nearly all $\mathrm{Si}-\mathrm{OH}-\mathrm{Al}$ sites on the external surface as the conversion of $1,3,5$-TIPB was found to be only $2 \%$ for silylated sample compared with $84 \%$ for the parent zeolite. In addition, TPDA, argon, and ethyltoluene sorption measurements as well as toluene conversion gave evidence that the concentration of strong Brønsted acid sites located in the pores remained nearly
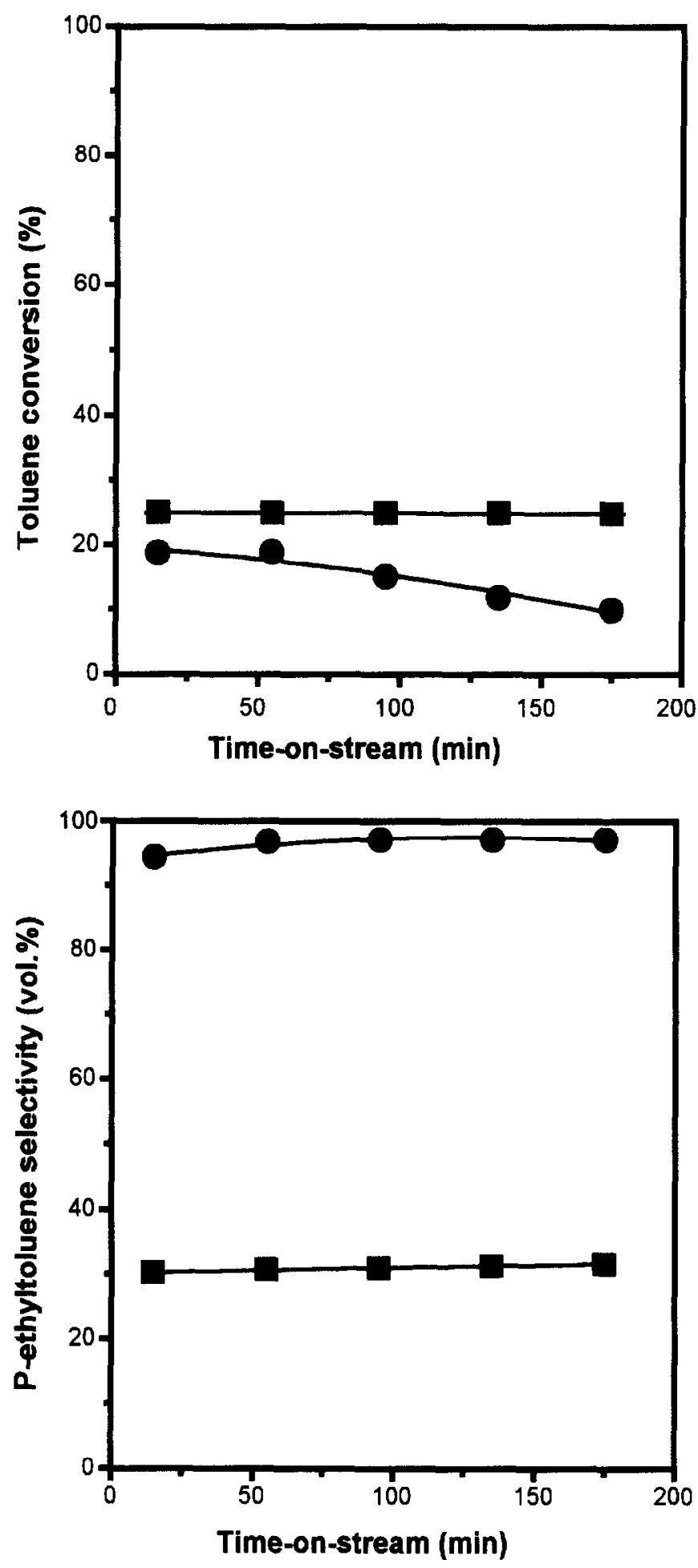

Figure 5 T-O-S dependence of toluene conversion and $p$ selectivity for parent HZSM-5 (ם) and silylated HZSM-5 (•). unchanged. This proves that a substantial increase in para-selectivity at high conversion levels can be achieved via silylation of the zeolite external surface.

\section{Diffusion of xylene and ethyltoluene isomers}

To establish the effect of coke deposits and zeolite surface silylation on the rates of transport of the individual dialkylaromatics, the diffusion of xylene and ethyltoluene isomers was investigated. The diffusion coefficients were estimated from the time-dependent uptake of the pure xylene and ethyltoluene isomers at constant temperature (for details see Refs. 15, 20-23). The uptake $(Q)$ is determined from the normalized intensity of one characteristic i.r. band of the adsorbate. Assuming that the HZSM-5 zeolite used consists of spherical particles $\left(r_{0}=0.5 \mu \mathrm{m}\right)$, the following equation was used to estimate the diffusion coefficients.

$$
Q_{t} / Q_{\infty}=6 / r_{0} \cdot(D t / p)^{0.5}
$$

In this equation, $Q$, denotes the uptake at time $(t)$ and $Q_{\infty}$ the uptake after equilibration. The slope of the linear part of the curve $\left(Q_{t} / Q_{\infty}\right.$ ranging from 0.3 to 0.6$)$ was used to estimate the diffusion coefficient $(D)$.

The uptake rates of $p$ - and $o$-xylene over HZSM- 5 deactivated under mild conditions (during $24 \mathrm{~h}$ of toluene alkylation with methanol) were found to be practically identical with those of the fresh HZSM-5. The low coke concentration led to both a partial decrease in the concentration of $\mathrm{OH}$ groups and the zeolite inner void volume but had no influence on transport rates of xylene molecules.

With severely deactivated ZSM-5 (highly coked zeolite), nearly no free bridging $\mathrm{OH}$ groups remained, as can be seen from Figure 2 (spectrum 3). The i.r. spectra indicated that $\mathrm{OH}$ groups were covered with strongly adsorbed polymethylated benzene molecules or with coke deposits, and only a few percent became free after outgassing the sample in vacuum at $600^{\circ} \mathrm{C}$. For this reason the uptake of xylenes or ethyltoluenes was practically negligible. Although it was difficult to estimate the effect of coking on the rates of transport for $p$ xylene or $p$-ethyltoluene, the uptake rates for parent and coked HZSM-5 seem to be comparable. Nevertheless, this fully coked zeolite exhibited substantial toluene conversion in both catalytic alkylation reactions (Tables 2 and 3). It follows that irreversibly bonded deposits contribute to some extent to the catalytic reaction.

The time-resolved i.r. spectra of sorbed p-ethyltoluene at $373 \mathrm{~K}$ on silylated ZSM-5 are shown in Figure 6. It is clearly seen that isomerization of $p$-ethyltoluene does not proceed under these experimental conditions. The dependence of the relative intensities of the specific i.r. absorption at $1,486 \mathrm{~cm}^{-1}$ (characteristic for adsorbed pethyltoluene on Brønsted acid sites) versus time of adsorption for parent and silylated HZSM-5 are given in Figure 7. A rough estimation of the diffusion coefficients of $p$-ethyltoluene indicates a substantial difference between HZSM- 5 , with a diffusion coefficient of about $6 \cdot 10^{-12} \mathrm{~cm}^{-2} / \mathrm{s}$ and silylated HZSM-5 with $D=$ $1.10^{-12} \mathrm{~cm}^{-2} / \mathrm{s}$. It indicates that silylation with bulky TEOS molecules not only blocks the external surface 


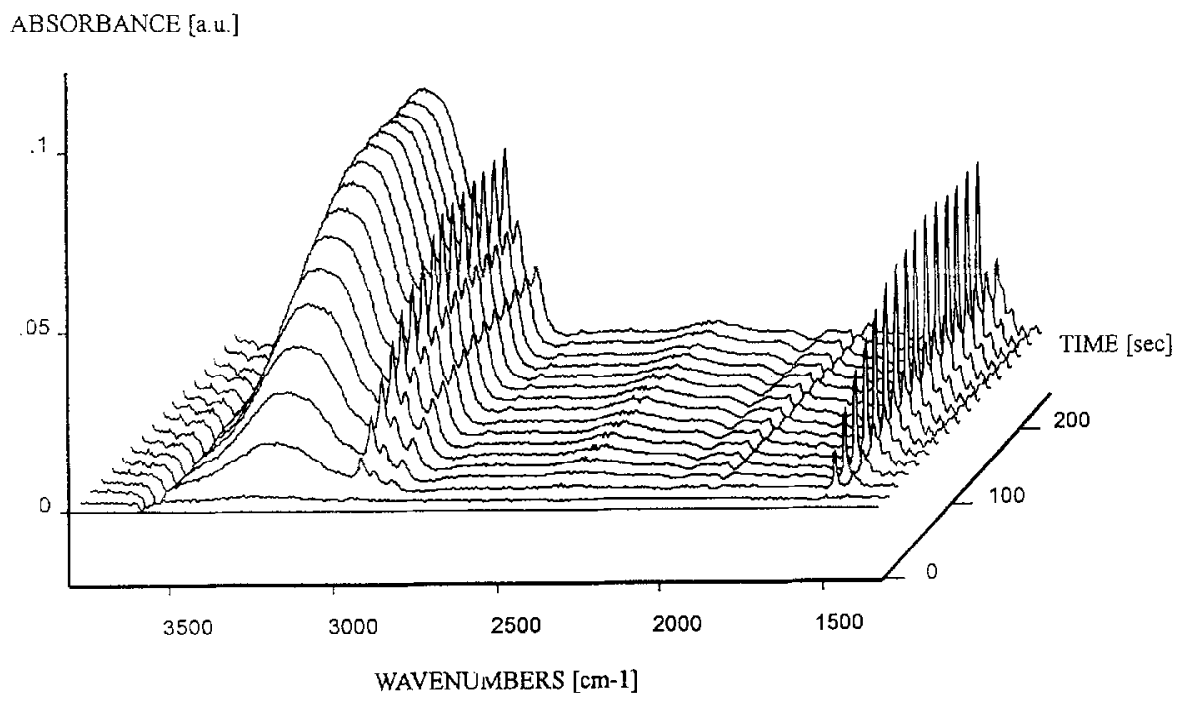

Figure 6 Time-resolved i.r. spectra of p-ethyltoluene adsorption on parent HZSM-5.

sites, but also decreases substantially the transport rate of p-ethyltoluene related to the enhancement of paraselectivity. This fact can be explained only by the narrowing and/or plugging of pore entrances of the zeolite channel system.

\section{CONCLUSIONS}

Coke (consisting mainly of strongly adsorbed polyalkylbenzenes) formed during the alkylation reaction is located in the bulk of the zeolite crystals, and it is not located specifically on the external surface. Although this low concentration of coke decreases the number of strong acid $\mathrm{OH}$ groups and zeolite inner void volume, no changes in the transport rates have been found for dialkylaromatic compounds. Moreover this coke can probably take part also in the reaction (e.g., isomerization).

No increase in para-selectivity has been observed for HZSM- 5 with coke covering the external surface. The presence of high concentrations of coke deposits

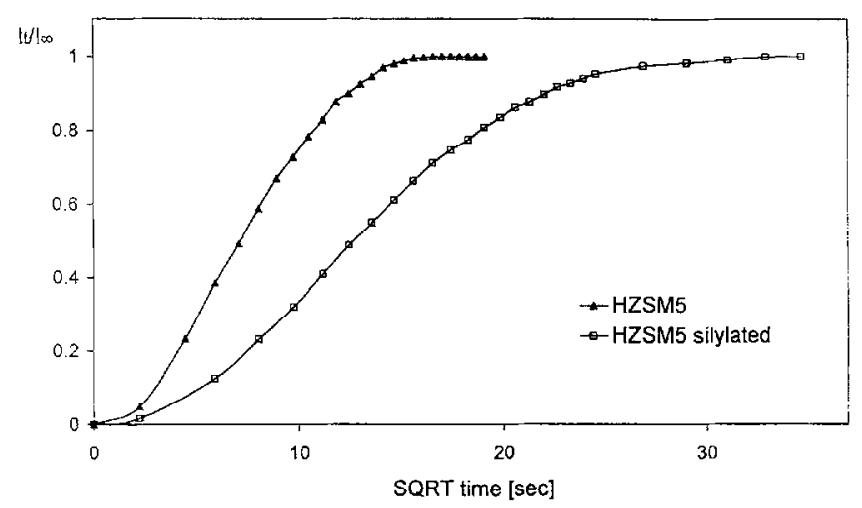

Figure 7 Time dependence of relative intensity of characteristic i.r. band of $p$-ethyltoluene on parent HZSM-5 and silylated ZSM-5. throughout the zeolite crystals has a negative effect on the resulting HZSM-5 para-selectivity. Surface silylation of HZSM-5 with tetraethylorthosilicate leads to blocking of $\mathrm{Si}-\mathrm{OH}-\mathrm{Al}$ groups on the excernal surface and to a substantial decrease in transport rate of $p$-ethyltoluene compared with the parent HZSM-5. Substantial enhancement of para-selectivity has been found after surface silylation of HZSM-5, which is a result of pore entrance narrowing rather than annihilation of the external acid sites.

All these results show that transport rates of the individual dialkylaromatic molecules play the decisive role in the enhancement of the zeolite para-selectivity.

\section{Acknowledgment}

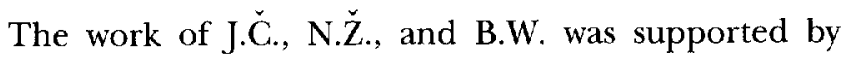
Grant 440408 from the Academy of Sciences of the Czech Republic. Partial support of this work by the Christian Doppler Society and the Fonds zur Förderung der wissenschaftlichen Forschung is acknowledged.

\section{REFERENCES}

1 Chen, N.Y., Keading, W.W. and Dwyer, T. J. Am. Chem. Soc. $1979,101,6783$

2 Keading. W.W., Chu, C, Young, L.B. and Butter, S.A. J. Catal. 1981, 67, 159

3 Olson, D. and Haag, W.O. ACS Symp. Ser. 1984, 248, 275

4 Chen, N.Y. J. Catal. 1988, 114, 17

5 Kumar, R. and Ratnasamy, P. J. Catal. 1989, 116, 440

6 Kumar, R. and Ratnasamy, P. J. Catal. 1989, 118, 68

7 Kumar, R., Rao, N.G. and Ratnasamy, P. Stud. Surf. Sci. Catal. 1989, 49, 1141

8 Mirth, G. and Lercher, J.A. J. Catal. 1991, 132, 244

9 Čejka, J., Wichterlová, B. and Bednářová, S. Appl. Catal. A: Gen. 1991, 79, 215 
10 Wichterlová, B. and Čejka, J. Catal. Lett. 1992, 16, 421

11 Mirth, G. and Lercher, J.A. J. Catal. 1994, 147, 199

12 Freankel, D. and Levy, M. J. Catal. 1989, 118, 10

13 Čejka, J., Wichterlová, B., Krtil, J., Křivánek, M. and Fricke, R. Stud. Surf. Sci. Catal. 1991, 69, 347

14 Corma, A. and Sastre, E. J. Chem. Soc. Chem. Commun. 1991, 594

15 Mirth, G., Čejka, J. and Lercher, J.A. J. Catal. 1993, 139, 24

16 Mirth, G., Cejka, J., Krtil, J. and Lercher, J.A. Stud. Surf. Sci. Catal. 1994, 88, 241
17 Guisnet, M. and Magnoux, P. Appl. Catal. 1989, 54, 1

18 Anderson, J.R., Chang, Y.-F. and Western, R.J. J. Catal. $1989,118,466$

19 Anderson, J.R., Dong, Q,-N., Chang, Y.-F. and Western, R.J. J. Catal. 1991, 127, 113

20 Breck, D.W. Zeolite Molecular Sieves, Wiley, New York, $1974,670-671$

21 Choudhary, V.R. and Singh, A.P. Zeolites 1986, 6, 206

22 Mirth, G. and Lercher, J.A. J. Phys. Chem. 1990, 95, 3736

23 Niessen, W. and Karge, H.G. Microporous Mater. 1993, 1, 1 